\title{
Characterization of Soot from Diesel-CNG Dual-Fuel Combustion in a CI Engine
}

Karthik Nithyanandan ${ }^{1}$, Yilu Lin ${ }^{1}$, Robert Donahue ${ }^{1}$, Xiangyu Meng ${ }^{3}$, Jiaxiang Zhang ${ }^{4}$, Chia-fon F. Lee ${ }^{1,2} *$

1. University of Illinois at Urbana-Champaign

2. Beijing Institute of Technology

3. Dalian University of Technology

4. Chongqing Chang'an Automobile Co. Ltd.

Corresponding Author:

Chia-fon F. Lee

Address: Mechanical Science and Engineering, 1206 W Green Street, Urbana, IL 61801, USA

Email: cflee@illinois.edu

(C) 2016. This manuscript version is made available under the Elsevier user license 


\section{Abstract}

The physico-chemical characterization of exhaust soot is very important in the design and operation of suitable after-treatment systems. The nanostructure and reactivity of soot depends strongly on the initial fuel identity and synthesis conditions. This paper presents the chemical composition, oxidation reactivity and nanostructural characteristics of particulate matter (PM) produced by a diesel engine operating with diesel/compressed natural gas (CNG) dual-fuel combustion. Raw, undiluted soot samples from pure diesel, $40 \% \mathrm{CNG}$ and $70 \% \mathrm{CNG}$ (energy-based substitution rate) combustion were collected from the exhaust pipe. Engine operation conditions were held at $1200 \mathrm{RPM}$ and $20 \mathrm{mg} / \mathrm{cycle}$ baseline load. For dual-fuel operation, split diesel injection (two injections) was used as the pilot. CNG was injected into the intake manifold. First, soot oxidation reactivity was characterized using thermogravimetric analysis (TGA). Transmission electron microscopy (TEM) was then used to determine the diameter of the spherules, and the morphology of agglomerates. Raman spectroscopy was employed to determine the graphitic nature of the soot. Finally, diffuse reflectance infrared Fourier transform spectroscopy (DRIFTS) was used to identify surface functional groups of soot samples. It was found that soot reactivity increased with increasing $\mathrm{CNG}$ content. TEM images revealed a higher variation in particle diameter with increasing CNG substitution. High resolution TEM (HRTEM) images showed that CNG70 soot displayed features of immature soot particles. Raman spectroscopy results showed that soot reactivity does not depend on the initial graphitic structure. DRIFTS showed increased concentration of aliphatic and oxygen functional groups, which explained the higher reactivity. This enhanced reactivity could also be due to more active sites available in CNG soot, as well as due to CNG soot being immature. Under this test condition and engine configuration, it can be concluded that the use of CNG affects the morphology and nanostructure of PM, and hence the oxidation reactivity of the soot.

\section{Keywords}

Diesel; Soot; Nanostructure; CNG; HRTEM; DRIFTS; Raman; TGA 


\section{Introduction}

Dual-fuel combustion, burning compressed natural gas (CNG) and diesel, is an attractive alternative to diesel because CNG is clean-burning, abundant, and has been shown to decrease particulate matter (PM) emissions. CNG is inexpensive, has low greenhouse gas emissions, and yields lower $\mathrm{NO}_{\mathrm{x}}$ and $\mathrm{CO}_{2}$ emissions $[1,2] . \mathrm{CNG}$ consumption has risen since 1995 due to tax incentives, increased CNG supply, and falling prices [3].

Performance and emissions of diesel/CNG dual-fuel combustion have been extensively studied. It has been shown that dual-fuel combustion can achieve efficiencies similar to that of diesel [4]. Unburned hydrocarbons (UHC) and carbon monoxide (CO) emissions are typically higher compared to pure diesel, however, significantly decreased soot emissions have been reported [5-8].

PM has been a serious concern for human health due to its direct and broad impact on the respiratory organs, as well as contributing to the global warming issue. Diesel exhaust gas is a major contributor to combustion-derived particulate-matter air pollution. As such, PM emission standards are continually evolving and becoming more stringent globally. The most common after-treatment method for soot reduction is to employ a diesel particulate filter (DPF) to trap soot particles. However, the design and effectiveness of these filters depend on soot properties. Thus, soot characterization has been the subject of several recent studies. Diesel soot generally takes the form of larger aggregates composed principally of smaller spherical particles called spherules and possessing characteristic structural properties. The nanostructure of soot depends strongly on the initial fuel identity and synthesis conditions, such as burning temperature, residence time, fuel properties, and fuel/oxygen ratio; the nanostructure in turn affects the oxidation reactivity of the soot [9-14]. Therefore, characterizing the physicochemical characteristics of soot is important and can provide crucial information to improve the design and operation of after-treatment systems. Common methods used to analyze soot structure and chemical properties are Transmission Electron Microscopy (TEM) [15-21], Thermogravimetric Analysis (TGA) 
[16, 19, 20, 21], Raman spectroscopy [19, 21-22], and Diffuse Reflectance Infrared Fourier Transformed Spectroscopy (DRIFTS) [9, 11, 21, 22]. Although soot morphology and nanostructure have been widely studied for other alternative fuels such as crude vegetable oil [9] and biodiesels [10, 11], there are no studies that have compared PM from diesel and diesel/CNG dual-fuel combustion.

In this study, we compare soot samples from pure diesel, $40 \% \mathrm{CNG}$, and $70 \% \mathrm{CNG}$ (energy-based substitution rate) collected from the exhaust pipe. First, soot oxidation reactivity was characterized using TGA. TEM was then used to determine the diameter of the spherules and the morphology of agglomerates. Raman spectroscopy was employed to determine the graphitic nature of the soot, and finally, DRIFTS was used to identify surface functional groups of soot samples.

\section{Nomenclature}

$\begin{array}{ll}\text { ATDC } & \text { After Top Dead Center } \\ \text { BTDC } & \text { Before Top Dead Center } \\ \text { BTE } & \text { Brake Thermal Efficiency } \\ \text { CAD } & \text { Crank Angle Degree } \\ \text { CI } & \text { Compression Ignition } \\ \text { CNG } & \text { Compressed Natural Gas } \\ \text { CO } & \text { Carbon Monoxide } \\ \text { DRIFTS } & \text { Diffuse Reflectance InfraRed Fourier Transform Spectroscopy } \\ \text { ECM } & \text { Engine Control Module } \\ \text { ECU } & \text { Engine Control Unit } \\ \text { EGT } & \text { Exhaust Gas Temperature } \\ \text { FSN } & \text { Filter Smoke Number } \\ \text { HRTEM } & \text { High Resolution Transmission Electron Microscopy } \\ \text { ICE } & \text { Internal Combustion Engine } \\ & \\ & \end{array}$




$\begin{array}{ll}\mathrm{NO}_{\mathrm{x}} & \text { Nitrogen Oxides } \\ \text { PB } & \text { Paper Blackening } \\ \text { PM } & \text { Particulate Matter } \\ \text { RPM } & \text { Revolutions per minute } \\ \text { TEM } & \text { Transmission Electron Microscopy } \\ \text { TGA } & \text { Thermo-Gravimetric Analysis } \\ \text { THC } & \text { Total Hydro-Carbons } \\ \text { UHC } & \text { Unburned Hydro-Carbons } \\ \Phi & \text { Equivalence Ratio } \\ \Lambda & \text { Lambda }(1 / \Phi)\end{array}$

\section{Experimental Setup and Methodology}

\subsection{Engine Parameters}

Experiments were carried out in an AVL 5402 single-cylinder diesel engine $($ displacement $=0.5 \mathrm{~L}$; compression ratio $=17.1)$. The engine was modified to run diesel/CNG dual-fuel mode by adding a Solaris CNG injection system, which was used to inject CNG into the intake manifold (port injection). Experiments were performed using No. 2 diesel and chemically pure methane was used to emulate CNG. The Solaris Diesel V4 control program was used to adjust the mass of CNG injected.

ETAS INCA v7 was used to control the electronic control module. In-cylinder pressure was measured using a Kistler pressure transducer, and $\mathrm{NO}_{\mathrm{x}}, \mathrm{UHC}, \mathrm{CO}$, and filter smoke number $(\mathrm{FSN})$ were measured using Horiba emissions analyzers. More details can be found in [4].

The CNG substitution was defined as the percentage of heat energy from CNG available in the cylinder. For example, $70 \% \mathrm{CNG}$ indicates that $70 \%$ of the energy input for the given engine condition was provided by CNG. Under a load equivalent to $20 \mathrm{mg} /$ cycle diesel (medium load), a CNG flow rate of $15 \mathrm{~L} / \mathrm{min}$ is equivalent to $70 \% \mathrm{CNG}$ substitution. Test conditions are summarized in Table 1 . 
Table 1. Test conditions (1200 RPM, 20 mg/cycle load)

\begin{tabular}{ll}
\hline Fuel & Diesel Injection Strategy \\
\hline \#2 Diesel & $5 \mathrm{mg} @ 12$ BTDC; $15 \mathrm{mg}$ @ 4 BTDC \\
CNG40 & $3 \mathrm{mg} @ 12$ BTDC; 9 mg @ 4 BTDC \\
CNG70 & $2 \mathrm{mg} @ 12$ BTDC; $4 \mathrm{mg} @ 4$ BTDC \\
\hline
\end{tabular}

\subsection{PM Sampling}

The PM sampling system was designed to allow simultaneous collection of raw PM on TEM grids, quartz fiber filter papers, and on stainless steel filters. The TEM grids (400 mesh Au) were inserted into the manifold through a Swagelok tee. The key advantage is that soot is directly collected in the aerosol phase onto TEM grids, bypassing filter collection and re-dispersal upon a TEM grid. Such processes cause agglomeration of soot aggregates and obscure aggregate recognition. For better high-resolution TEM (HRTEM) analysis, sampling was done on lacey carbon grids. PM was simultaneously collected on quartz (Pall Tissuquartz filters) and stainless steel filters using a vacuum pump system. PM collected on TEM grids was subjected to TEM, the quartz filters were used for Raman spectroscopy, and the PM was carefully scraped from the stainless steel filters for DRIFTS and TGA analysis.

\subsection{Diagnostic Techniques}

$T G A$

A TA Instruments Q50 was used to perform TGA. The sample was loaded in an alumina crucible and placed inside a furnace, where the temperature was increased following a user-defined program (Table 2) and the weight loss was continuously recorded. A sample mass of $3 \mathrm{mg}$ was used in all tests. This value was selected based on repeatability.

Table 2. TGA heating program

\begin{tabular}{l} 
1. Initial atmosphere: $\mathrm{N}_{2}$ \\
2. Ramp $3{ }^{\circ} \mathrm{C} / \mathrm{min}$ to $45^{\circ} \mathrm{C}$ \\
3. Ramp $10{ }^{\circ} \mathrm{C} / \mathrm{min}$ to $400{ }^{\circ} \mathrm{C}$ \\
4. Isothermal for 30 min \\
5. Changing atmosphere: air \\
6. Ramp $10^{\circ} \mathrm{C} / \mathrm{min}$ to $850^{\circ} \mathrm{C}$ \\
7. Isothermal for $10 \mathrm{~min}$ \\
\hline
\end{tabular}


To perform different levels of image analysis that include macro- (aggregate), micro- (spherule) and nano-scale (nanostructure), a 200-kV field emission TEM (JEOL 2100 CRYO TEM) was used to take high-resolution bright field images. Depending on the soot samples, the applied magnifications varied between 40,000x and 500,000x. For every sample, images of soot aggregates at more than forty locations were recorded. Digital images were acquired by Gatan image software.

Photographs were taken at various locations across the grid surface due to the insensitivity of soot concentration to grid position in the exhaust stream. For image comparison between samples, images were taken at similar magnification, while the sampling times were also identical. During the present sampling, no dilution or impaction was used, preventing condensation/nucleation of new particles or aggregate breakup upon deposition. Measurements were usually repeatable within the experimental uncertainties, which were dominated by the consideration of a finite number of particulates, the dependence of sampling on size and morphology, and image analysis biases [15].

\section{Raman Spectroscopy}

Raman spectra were acquired with a laser Raman confocal microscope (Nanophoton RAMAN11). The excitation wavelength of the Nd:YAG laser was $532 \mathrm{~nm}$; the sample was illuminated through an objective lens $(10 \mathrm{x}$, Numerical aperture $(\mathrm{NA})=1.2 ;)$. The profile of the laser was shaped into a line using a cylindrical lens. Raman scattered light from the illuminated line was collected with the same objective lens and guided to the confocal slit of a spectrograph (Czerny-Turner type, $f=500 \mathrm{~mm}$ ). The slit width was fixed at $60 \mu \mathrm{m}$. The scattered light was dispersed by a 1200 -groove $\mathrm{mm}^{-1}$ grating, and the spectra were recorded by a thermoelectrically cooled CCD camera $\left(-70^{\circ} \mathrm{C}, 1340 \times 400\right.$ pixels $)$. Spectra of the samples were in the range of $100-3600 \mathrm{~cm}^{-1}$. A 120 second exposition time and a source power of 0.2 $\mathrm{mW}$ were used to avoid altering or burning the sample. Interference from fluorescence was detected in the Raman spectra of all PM samples. This can be produced by the presence of polycyclic aromatic 
hydrocarbons (PAHs) [9]. Three Lorentzian functions (3L) for G band (1580 $\left.\mathrm{cm}^{-1}\right)$, D1 band $\left(1360 \mathrm{~cm}^{-1}\right)$, D4 band $\left(1180 \mathrm{~cm}^{-1}\right)$ and one Gaussian function $(1 \mathrm{G})$ for D3 band $\left(1500 \mathrm{~cm}^{-1}\right)$ were used [9]. Several different spots were analyzed and averaged for each sample to improve the statistical significance.

\section{DRIFTS}

Surface functional groups of the samples were analyzed using DRIFTS. A Thermo Nicolet Nexus 670 spectrometer with a MCT detector and a Spectratech diffuse reflectance accessory were used. Spectra were recorded from 4000 to $800 \mathrm{~cm}^{-1}$ by collection of 60 scans at $1 \mathrm{~cm}^{-1}$ resolution. Raw soot was dispersed on a gold mirror, and subjected to DRIFTS. DRIFT spectra of both the background (clean gold mirror) and the loaded mirror were acquired. DRIFTS was initially attempted directly on TEM grids containing soot, however, this did not yield a sufficiently strong signal and hence soot particles were directly dispersed on gold mirrors.

\section{Results and Discussion}

\subsection{Combustion Characteristics and Emissions}

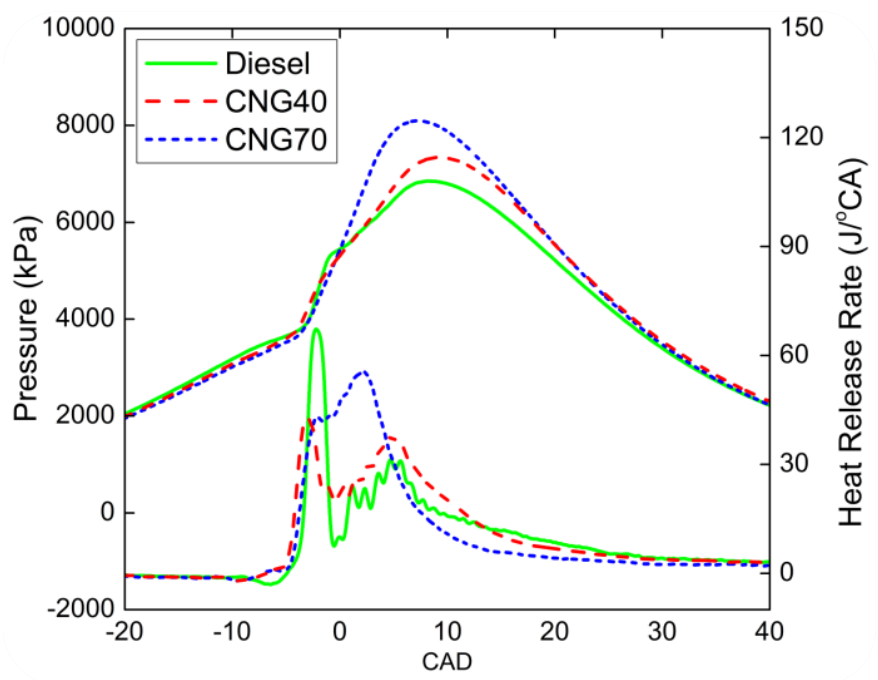

Figure 1. In-cylinder pressure of soot samples

Figure 1 shows combustion pressure and heat release rate curves for the cases tested. It is observed that the combustion phasing progressively gets advanced with increasing CNG substitution, and the peak pressure steadily increases. The CA50 of diesel, CNG40 and CNG70 are 6.0625, 5.5625 and 2.5625 CAD 
(ATDC), respectively. Table 3 shows various combustion characteristics for different substitution rates.

The ignition delay increases, while the combustion duration decreases with increasing CNG. The difference in ignition delay and combustion duration between diesel and CNG70 is 0.7 and 6 degrees, respectively. The equivalence ratio $(\Phi)$ increases with increasing CNG substitution because the increased CNG displaces air. The longer ignition delay results in a higher peak pressure, which subsequently increases the $\mathrm{NO}_{\mathrm{x}}$ emissions. The decreased FSN and increased $\mathrm{HC}$ and $\mathrm{CO}$ emissions with increasing CNG content is consistent with the literature $[4,5,8,23]$.

Table 3. Combustion characteristics and emission of tested fuels

\begin{tabular}{llllllll}
\hline Fuel & $\begin{array}{l}\text { Equivalence } \\
\text { ratio }(\Phi)\end{array}$ & $\begin{array}{l}\text { Ignition } \\
\text { Delay }(\mathrm{CAD})\end{array}$ & $\begin{array}{l}\text { Combustion } \\
\text { Duration }(\mathrm{CAD})\end{array}$ & $\begin{array}{l}\mathrm{NO}_{\mathrm{x}} \\
(\mathrm{ppm})\end{array}$ & $\begin{array}{l}\mathrm{HC} \\
(\mathrm{ppm})\end{array}$ & $\begin{array}{l}\mathrm{CO} \\
(\% \text { vol. })\end{array}$ & FSN \\
\hline No. 2 Diesel & 0.66 & 9.125 & 23 & 680 & 26 & 0.04 & 0.03509 \\
CNG40 & 0.98 & 9.3125 & 21.5 & 850 & 148 & 1.09 & 0.01868 \\
CNG70 & 1.11 & 9.8125 & 17 & 1020 & 164 & 2.21 & 0.00470 \\
\hline
\end{tabular}

\subsection{TGA}

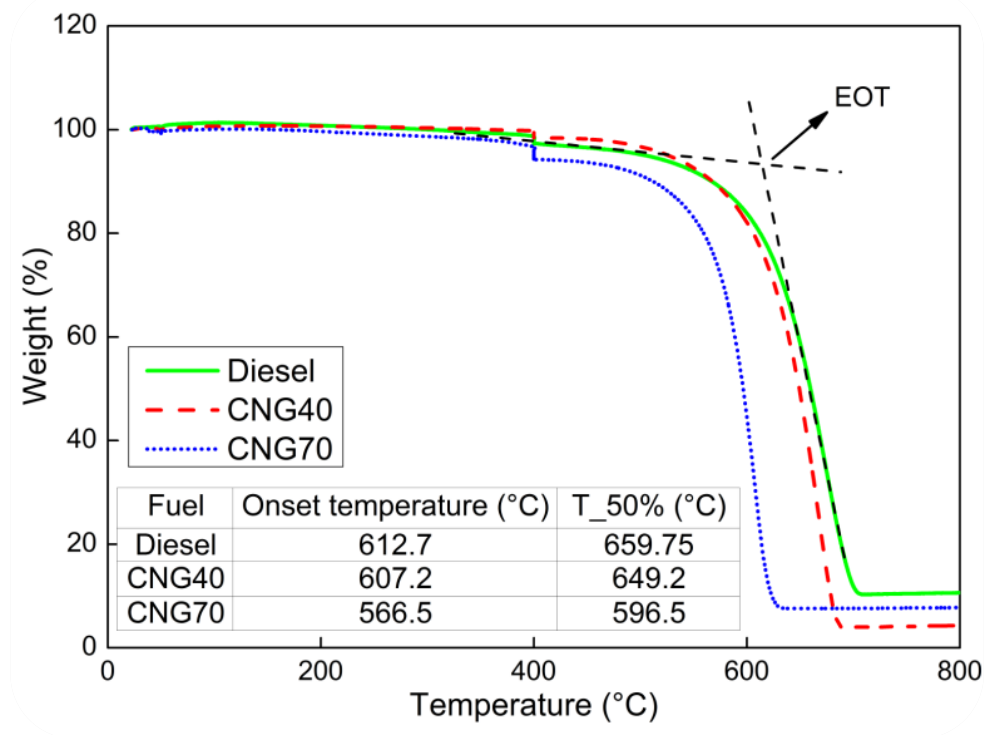

Figure 2. TGA profiles (mass \% lost) of soot samples

Figure 2 shows the thermogravimetric profiles for the soot samples. Mass reduction started at lower temperature for both CNG soot samples, indicating higher oxidation reactivity with respect to diesel soot. The drop in mass observed at $400{ }^{\circ} \mathrm{C}$ is due to the devolatilization process, wherein volatile organic 
fractions (VOF) are removed. In order to further examine the differences in reactivity, two parameters were calculated: (i) the extrapolated onset temperature (EOT), calculated as it is indicated in Figure 2 and (ii) $\mathrm{T}_{50 \%}$, the temperature at which the $50 \%$ of carbon was converted [20]. This information has been provided in Figure 2 (inset). Both CNG soot samples showed an earlier onset temperature as well as a lower $\mathrm{T}_{50 \%}$. These temperatures were significantly lower for $\mathrm{CNG} 70$, indicating that a higher $\mathrm{CNG}$ content increases reactivity of the soot. This implies that after-treatment systems could be designed to operate at lower temperatures with the use of diesel/CNG dual-fuel combustion.

The higher reactivity of $\mathrm{CNG}$ soot samples after $500{ }^{\circ} \mathrm{C}$, in comparison with diesel soot, could be due to a higher content of aliphatic and oxygen functional groups (discussed further in section 3.5). It could also be attributed to more active surface sites which enable chemical reactions [26]. Also, the drop in soot mass due to devolatilization is higher for CNG70. It has been reported that the specific area of the soot particles can increase during VOF desorption [13]. Thus the increased surface area due to VOF removal could also enhance soot oxidation. Although speculative, it is possible that CNG soot leads to capsule-type oxidization (faster than surface burning), as observed for biodiesel soot [9].

\subsection{TEM}

\section{TEM Macrostructure Observations}

Figure 3 shows TEM images of the three soot samples; the lacey carbon mesh is visible in figures (c) (f). Many spherules agglomerated to form aggregates of fractal-like geometry. From Figure 3(a) and (b), some familiar features of diesel soot can be observed. First, there was significant variation in overall aggregate sizes. Secondly, particulates had different shapes with grape-like structures [18]. For diesel soot, spherules had nearly uniform diameters. Also, the boundaries between spherules were unclear. In comparison, Figure 3(c), (d) and (e), (f) show typical soot macrostructures observed in CNG40 and CNG70 samples, respectively. CNG soot is less clumped due to decreased loading; note that the sampling times were similar. CNG soot is long, highly curved, and has more complex chains compared to diesel 
soot. CNG chains are looser and more open-looped, containing a single chain of particles, whereas diesel soot is more tightly packed. Another notable feature of CNG70 soot is that the spherules are less circular and show irregular, distorted shapes; these are signs of immature soot [13].

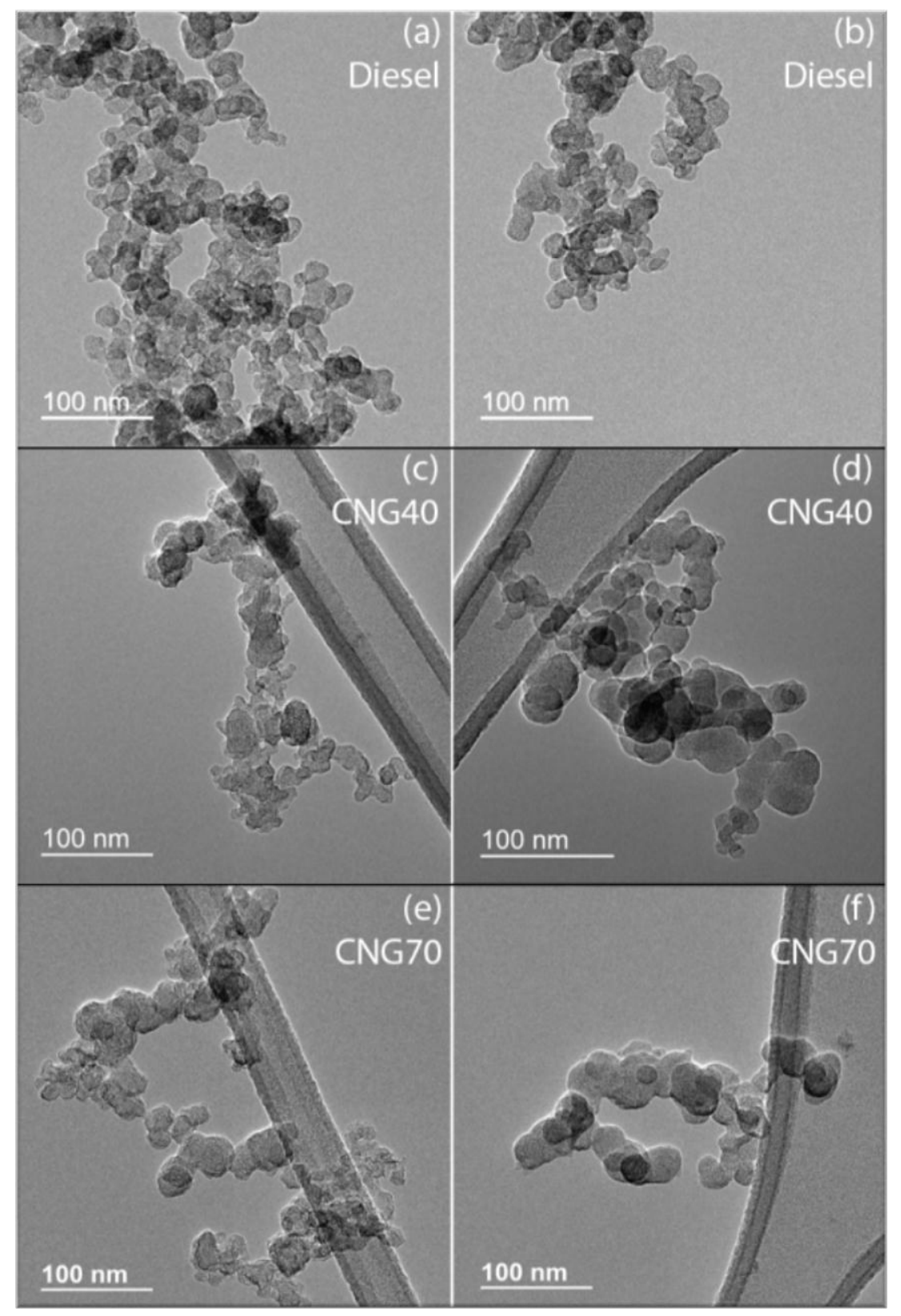

Figure 3. Typical TEM images of soot samples 


\section{Soot Aggregate Characteristics}

The curves in Figure 4 indicate that diesel soot aggregates contain the largest number of spherules compared to CNG soot aggregates of similar size. The size of soot aggregates depends on the rate of two reaction mechanisms: surface growth and collisional aggregation [24]. In the collisional aggregation pathway, the frequency of collisions between primary soot particles in CNG cases is lower than that of diesel. Methane, the main component of $\mathrm{CNG}$, does not contain carbon-carbon bonds, substantially lowering the probability of benzene ring formation and thus the formation of aromatic hydrocarbons and PAHs [8]. Fewer precursors generated during combustion will lead to less frequent collisions among particles, leading to fewer soot particles within aggregates.

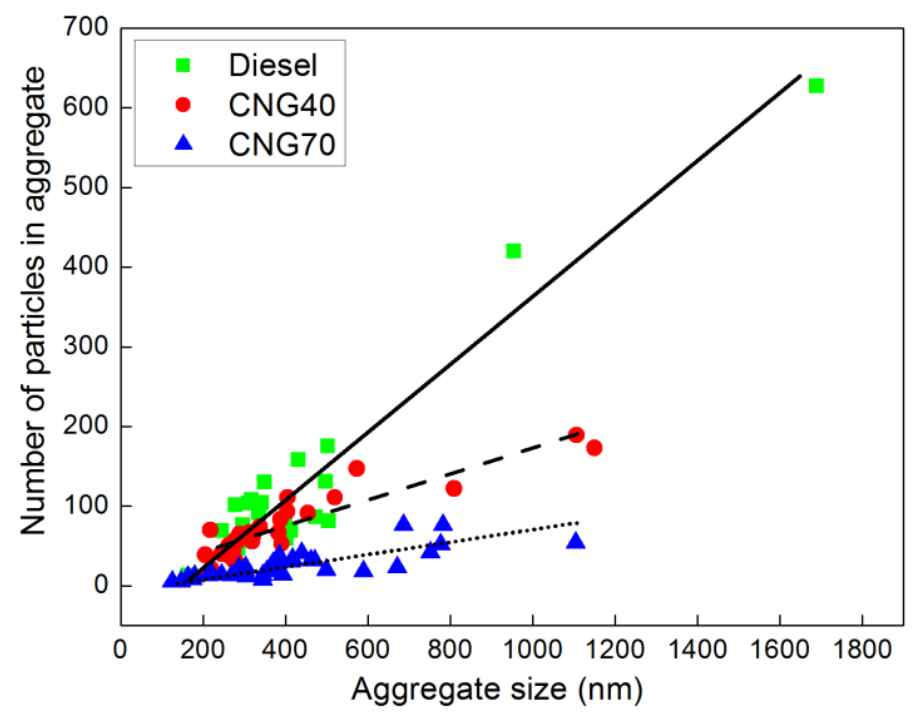

Figure 4. Relationship between spherules per aggregate and aggregate size

\section{Primary Soot Particle Diameter Distributions}

Spherule diameter was measured manually using ImageJ software. The diameter was determined by fitting circles to each spherule. Figure 5 shows the distribution of spherule sizes; the distribution functions were normalized for an even comparison. For each of the cases, more than 1000 particles from roughly 50 images were counted and measured. 


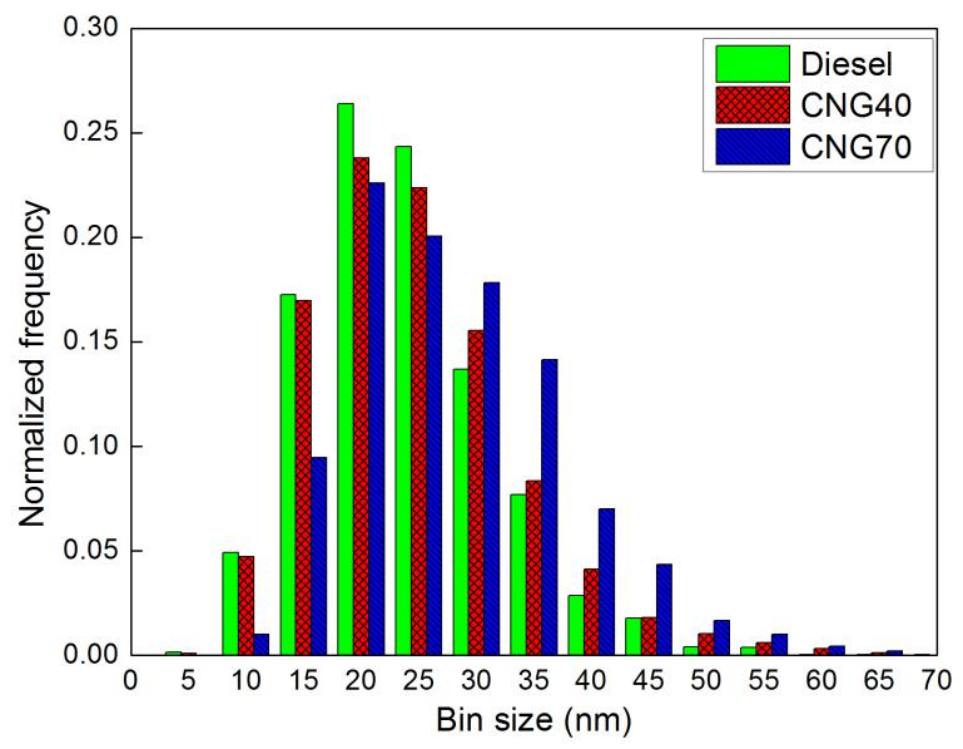

Figure 5. Normalized spherule size distributions

Figure 5 shows that CNG soot has significantly higher variation in spherule size distributions, showing a wider distribution curve. Diesel has the greatest population for particle sizes smaller than $25 \mathrm{~nm}$. For particles greater than $25 \mathrm{~nm}$, diesel has the lowest population. This indicates that the distribution of CNG cases shifts toward larger spherule sizes with increasing CNG.

Table 4 Statistics of Spherule Diameter from Tested Fuels (Unit: nm)

\begin{tabular}{llll}
\hline & D100 & CNG40 & CNG70 \\
\hline Mean & 21.19 & 22.15 & 25.63 \\
S.D. & 8.03 & 9.10 & 9.49 \\
\hline
\end{tabular}

Statistical comparisons were made between soot spherule diameter data between samples from D100 versus samples from CNG40 and CNG70, as shown in Table 4. Two-sided Student's t-test with $\mathrm{p}=0.05$ was used to test for significant differences between sample set means. It was found that the differences between spherule particle diameters were statistically significant at the $95 \%$ confidence level. This result further concluded that the addition of CNG increased the mean diameter of soot spherule size.

The particle size is due to the competing result of surface growth and soot oxidation processes. Increasing CNG substitution results in an increased $\Phi$ which promotes particle nucleation and growth, while suppressing particle oxidation [15]. In the model proposed by Frenklach et al. [26], the reaction rate 
of surface growth and the oxidation reaction is proportional to the number density of active sites. CNG soot likely contains more active sites and thus grows faster, resulting in larger particle sizes. This argument can be further supported by the enhanced reactivity observed using TGA. On the other hand, the oxidation process during combustion and post-combustion decreases the particle size. It can be seen from Figure 2 that the bulk-averaged combustion temperature is higher for CNG cases (higher peak pressure), implying an enhanced oxidation reaction rate. However, another key parameter is the residence time allowed for oxidation reaction. From Table 3, dual-fuel combustion shows significantly shorter combustion durations, i.e., a shorter residence time, which limits the advancement of oxidation reactions in CNG cases. Therefore, it seems that the residence time may have a larger impact on soot oxidation (and thus particle size) than the combustion temperature.

\section{HRTEM Nanostructure}

HRTEM images were studied to examine the nanostructure of spherules. On a nanometric scale, a diesel spherule presents two distinct parts: an inner core and an outer shell, each with different structures. In the characteristic shell/core nanostructure, graphene layers are parallel to the external surfaces in the outer shell, but are randomly arranged in a turbostratic (not well aligned) state in the central core region [14]. A particle with a slightly aggregated structure, called an immature particle, generally exhibits an irregular shape and is not fully developed. It is formed from the coalescence of a number of pre-formed particles. A particle with a typical inner core--outer shell structure, called a mature particle, contains one or several nucleation sites. The inner core is surrounded by concentrically ordered graphene layers (outer shell) [10].

Figure 6 shows a comparison between HRTEM images of the three soot samples. The nanostructure observed for diesel soot is in agreement with the literature. Diesel and CNG40 soot seem to be more ordered, i.e., displaying clear concentric graphitic layers. They also exhibit signs of a mature soot particle. On the other hand, CNG70 soot has a relatively random, incoherent arrangement of lamellae 
without a clear center. It was also observed in Figure 6 that CNG70 soot exhibited irregular shaped spherules. Therefore, it can be concluded that CNG70 soot is immature. This can be attributed to two factors during the combustion process: first, $\mathrm{CNG}$ addition reduces formation of soot precursors and hence favors the formation of particles with aggregated structures, rather than mature particles; second, as mentioned earlier, the shorter residence time is insufficient for the soot to develop an inner core and outer shell structure. The HRTEM images of CNG70 soot also seem comparable to those obtained for immature soot from premixed methane flames in a burner, in that they are comprised of disordered carbon without a clear structural order [16]. Given that immature soot is more susceptible to oxidation [13, 16], it is expected that it would be more reactive, which agrees with TGA results.
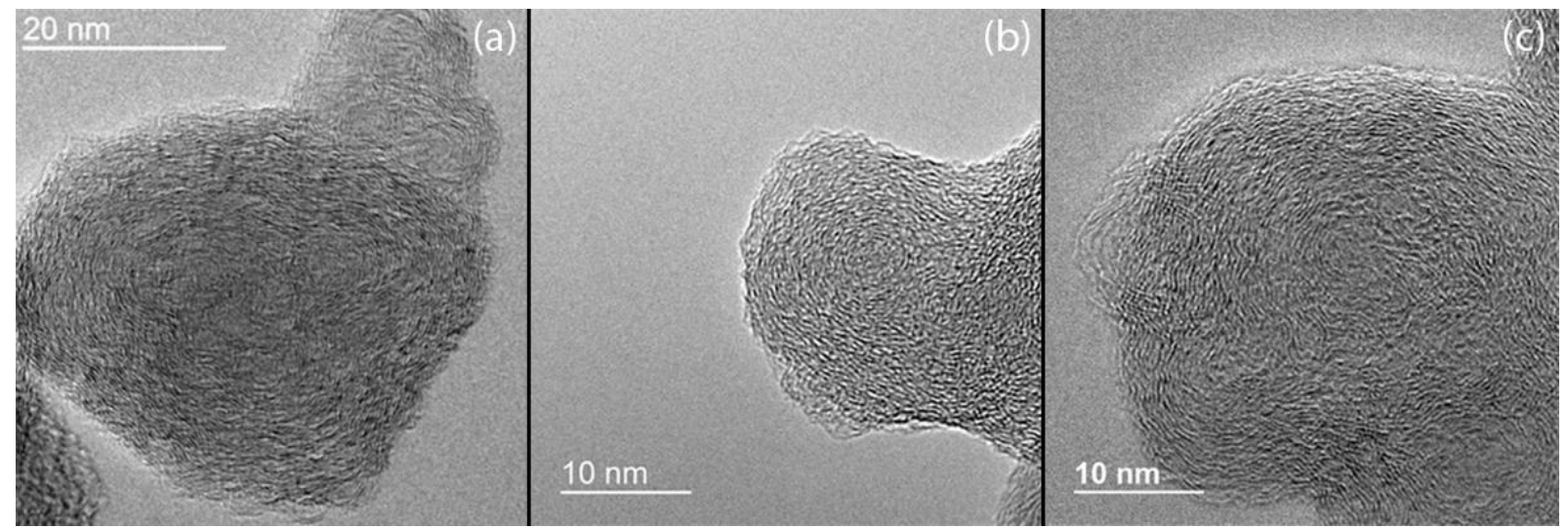

Figure 6. Typical HRTEM images of (a) diesel (b) CNG40 (c) CNG70

\subsection{Raman Spectroscopy}

Raman spectroscopy provides information about the graphitic nature of carbonaceous material. The D3 band $\left(\sim 1500 \mathrm{~cm}^{-1}\right)$ represents impurities of the graphene lattice, due to interstitials defects or amorphous carbon, such as that associated with organic molecules, fragments or functional groups; the D1 $\left(\sim 1350 \mathrm{~cm}^{-1}\right)$ band has been related to the degree of order (edge sites and basal defects) of the graphene lattice. A higher intensity in these bands relative to the $\mathrm{G}$ band indicates a larger amount of impurities and a less ordered nanostructure, which could lead to higher reactivity. Although there exist several criteria to 
describe carbon structural information based on Raman spectra, in this work the criterion of ID/IG intensity ratio has been adopted [9]. The uncertainties in ID/IG values were \pm 0.03 .

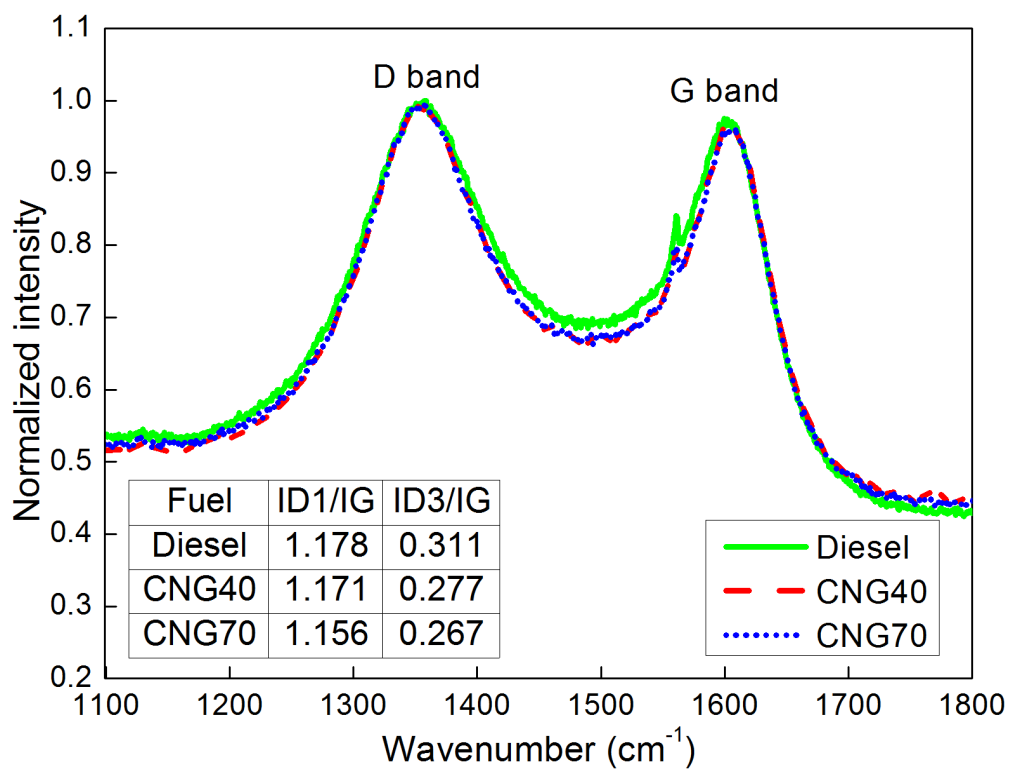

Figure 7. Raman spectra of soot samples

Differences were observed among the Raman spectra of all soot samples. Figure 7 shows that both CNG soot samples exhibited similar spectra, but they differ from diesel soot as follows: (i) CNG soot had slightly lower width in the diesel D1 band $\left(\sim 1350 \mathrm{~cm}^{-1}\right)$ and (ii) the G band (1580 cm-1) of CNG soot had a slightly lower intensity. Figure 7 (inset) shows ID1/IG, ID3/IG intensity ratios for all soot samples. No significant differences were observed between CNG soot samples. Diesel soot exhibited more nanostructural irregularities. Therefore, although CNG soot is more reactive, the initial structure and orderliness does not directly affect soot reactivity. Similar results were observed in [2727]. 


\subsection{DRIFTS}

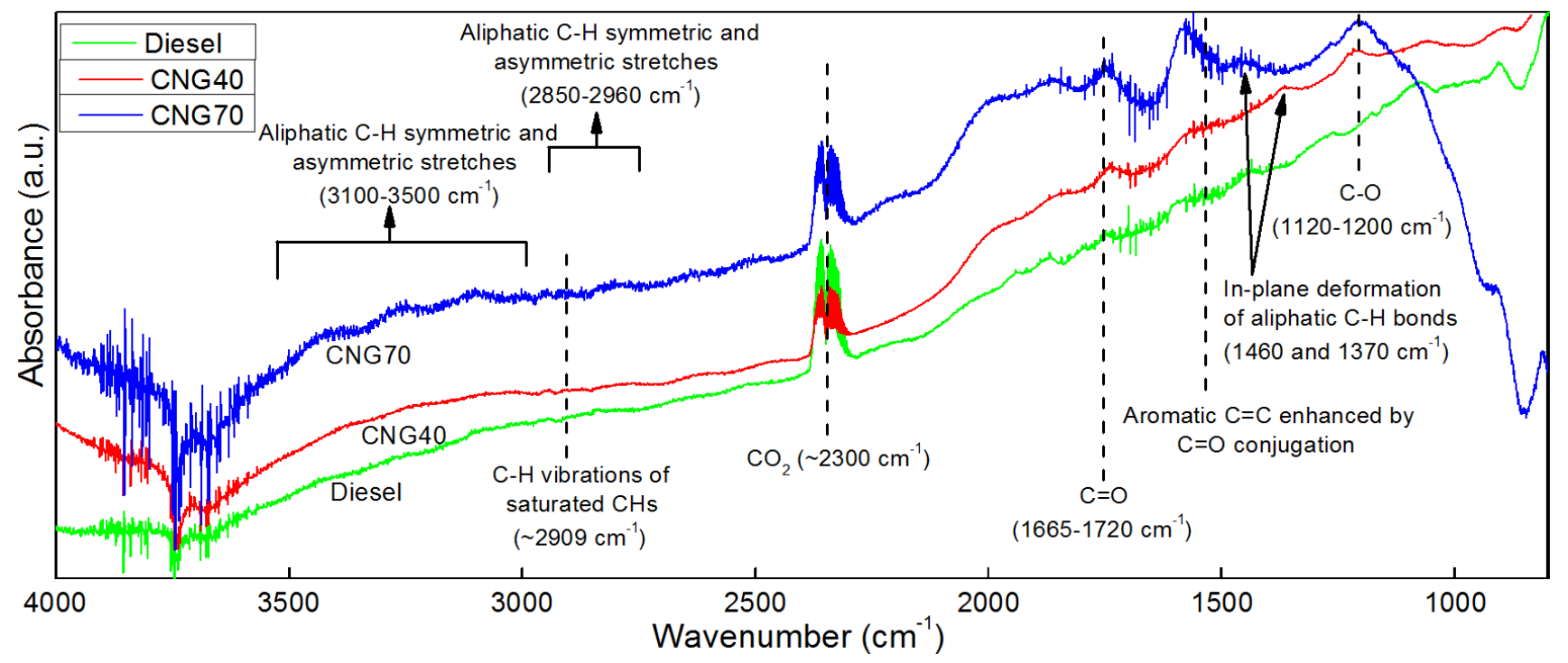

Figure 8. DRIFT spectra of soot samples

Figure 8 shows the DRIFT spectra of the three soot samples. The most prominent absorption bands are observed in the range $1400-1700 \mathrm{~cm}^{-1}$ and in the range $1100-1200 \mathrm{~cm}^{-1}$. These two bands correspond to $\mathrm{C}=\mathrm{O}\left(1660-1750 \mathrm{~cm}^{-1}\right)$ and $\mathrm{C}-\mathrm{O}\left(1120-1220 \mathrm{~cm}^{-1}\right)$ stretching of carboxylic acids $[12,20,27]$. The increasing sharpness of the peak at $\sim 1740 \mathrm{~cm}^{-1}$ as CNG content increases, suggests a higher degree of oxygen functionality for CNG soot [11,27].

The peaks at $2850-2960 \mathrm{~cm}^{-1}$ (aliphatic C-H symmetric and asymmetric stretches) are present but not significant in the spectra. The presence of aliphatic groups is further suggested by the peaks in the range of $\sim 1460$ and $\sim 1370 \mathrm{~cm}^{-1}$ (in-plane deformation of aliphatic C-H bonds) [12]. CNG40 shows a peak at $1370 \mathrm{~cm}^{-1}$, which is absent in the other samples; meanwhile, CNG70 shows a sharp peak at 1460 and another at $\sim 1590 \mathrm{~cm}^{-1}$ (aromatic $\mathrm{C}=\mathrm{C}$ enhanced by $\mathrm{C}=\mathrm{O}$ conjugation), which are not present in the others. The concentration of hydroxyl groups (peaks at $~ 3100-3500 \mathrm{~cm}^{-1}$ ) [11] is also more apparent for the CNG70 case. The peak at $2909 \mathrm{~cm}^{-1}$ is characteristic of the $\mathrm{C}-\mathrm{H}$ vibrations of saturated hydrocarbons, indicating the presence of $\operatorname{sp}^{3}$ hybridized carbon, which is related to the graphitic structure of soot $[9,20]$. 
This peak is similar for the three samples; this agrees with the results obtained from the Raman spectra, which showed no major differences in the $\mathrm{I}(\mathrm{D}) / \mathrm{I}(\mathrm{G})$ ratios.

High content of aliphatic hydrocarbons ( $\mathrm{C}-\mathrm{H}$ groups) are more important in governing soot oxidation reactivity than other oxygenated surface functional groups, and their higher H/C ratio and reactivity compared with aromatics, enhances the soot reactivity [9, 28]. Moreover, initial oxygen groups have a definite correlation with the rate constant, implying a strong influence on oxidation behavior [27]. Finally, it has been suggested that higher soot reactivity is related to the concentration of hydroxyl groups [11]. As such, CNG soot satisfies all the above criteria, which explains its higher reactivity. The higher presence of aliphatic groups in CNG soot could be explained by the effect of methane, which does not contain $\mathrm{C}=\mathrm{C}$ bonds, thus lowering the formation of aromatic hydrocarbons. The DRIFT spectrum recorded in the present work fails to detect any significant peak around $3050 \mathrm{~cm}^{-1}$ (aromatic C-H stretch) [9], which further supports this theory.

\section{Conclusions}

Physicochemical characterization of soot from diesel/CNG dual-fuel combustion was performed using TGA, HRTEM, Raman spectroscopy and DRIFTS. Based on the observations, the following conclusions can be made:

1. Soot oxidation reactivity increased significantly with increasing CNG content. Both the onset and the $\mathrm{T}_{50 \%}$ temperatures were considerably lower for CNG soot. This implies that after-treatment systems could be designed to operate at lower temperatures with the use of diesel/CNG dual-fuel combustion.

2. TEM results showed that number of particles in an aggregate decreases, as well as aggregate size, with increasing $\mathrm{CNG}$ due to less collisional aggregation. CNG soot has a larger distribution of particle sizes and the distribution shifts towards larger particle size with increasing CNG due to higher surface growth rate. 
3. HRTEM images showed that CNG70 soot appears to be immature due to shorter residence times (in spite of higher combustion temperature).

4. Raman spectra showed no differences between the soot samples, indicating that initial nanostructure and orderliness of graphene layers does not affect reactivity. Therefore, Raman spectroscopy might not be a reliable method to assess reactivity for the cases tested.

5. DRIFTS showed that CNG soot had markedly higher concentration of aliphatic groups and oxygen functional groups, which explains the high oxidation reactivity.

This is the first study of its kind for Diesel/CNG soot characterization. With increase in CNG consumption as well as dual-fuel engines, it is necessary to understand how CNG soot differs from conventional diesel soot. Under the tested condition, it can be concluded that the use of CNG affects the morphology, structure, chemical composition, and hence the reactivity of soot, which is relevant for design and operation of aftertreatment devices.

\section{Acknowledgments}

This material is partially based upon work supported by FAW Group Corporation, China. Any opinions, findings, and conclusions or recommendations expressed in this publication are those of the author(s) and do not necessarily reflect the views of FAW. This work was carried out in part in the Frederick Seitz Materials Research Laboratory Central Research Facilities, University of Illinois. Special thanks are extended to Dr. Julio Soares from the Laser and Spectroscopy Facility for his help in interpreting DRIFTS results. 


\section{References}

1. McTaggart-Cowan GP, Jones HL, Rogak SN, Bushe WK, Hill PG, Munshi SR. The Effects of High-Pressure Injection on a Compression-Ignition, Direct Injection of Natural Gas Engine. ASME. J. Eng. Gas Turbines Power.2006;129(2):579-588. doi:10.1115/1.2432894.

2. J. Olsen, R.J. Crookes, K.D.H. Bob-Manuel, Experiments in Dual Fuelling a Compression Ignition Engine by Injecting Di-Methyl Ether as a Pilot Fuel to Ignite Varying Quantities of Natural Gas, SAE Technical Paper 2007-01-3624 (2007). Technical Paper2007-08-05 DOI: $10.4271 / 2007-01-3624$

3. Natural Gas Consumption by End Use - US Energy Information Administration https://www.eia.gov/dnav/ng/ng_cons_sum_dcu_nus_a.htm (September 2015).

4. Nithyanandan K, Zhang J, Li Y, et al. Diesel-like Efficiency using CNG/Diesel Dual-fuel Combustion. ASME. J. Energy Resour. Technol. 2016;():. doi:10.1115/1.4032621.

5. A.M. Namasivayam, T. Korakianitis, R.J. Crookes, K.D.H. Bob-Manuel, J. Olsen, Biodiesel, emulsified biodiesel and dimethyl ether as pilot fuels for natural gas fuelled engines, Applied Energy, Volume 87, Issue 3, March 2010, Pages 769-778, ISSN 0306-2619, http://dx.doi.org/10.1016/j.apenergy.2009.09.014.

6. T. Korakianitis, A.M. Namasivayam, R.J. Crookes, Diesel and rapeseed methyl ester (RME) pilot fuels for hydrogen and natural gas dual-fuel combustion in compression-ignition engines, Fuel, Volume 90, Issue 7, July 2011, Pages 2384-2395, ISSN 0016-2361, http://dx.doi.org/10.1016/j.fuel.2011.03.005.

7. S. H. Yoon, C. S. Lee, Experimental investigation on the combustion and exhaust emission characteristics of biogas-biodiesel dual-fuel combustion in a CI engine, Fuel Processing Technology, Volume 92, Issue 5, May 2011, Pages 992-1000, ISSN 0378-3820, http://dx.doi.org/10.1016/j.fuproc.2010.12.021. 
8. G. Karavalakis, T. D. Durbin, M. Villela, J. W. Miller, Air pollutant emissions of light-duty vehicles operating on various natural gas compositions, Journal of Natural Gas Science and Engineering, Volume 4, January 2012, Pages 8-16, ISSN 1875-5100, http://dx.doi.org/10.1016/j.jngse.2011.08.005.

9. J.R. Agudelo, A. Álvarez, O. Armas, Impact of crude vegetable oils on the oxidation reactivity and nanostructure of diesel particulate matter, Combustion and Flame, Volume 161, Issue 11, November 2014, Pages 2904-2915, ISSN 0010-2180, http://dx.doi.org/10.1016/j.combustflame.2014.05.013.

10. X.J. Man, C.S. Cheung, Z. Ning, K.F. Yung, Effect of Waste Cooking Oil Biodiesel on the Properties of Particulate from a DI Diesel Engine, Aerosol Science and Technology, Volume 49, Issue 4, 2015, pp 199-209, DOI:10.1080/02786826.2015.1016214.

11. M. Lapuerta, J. Rodriguez-Fernandez, J. Sanchez-Valdepenas, M. Salgado, Multi-Technique Analysis of Soot Reactivity from Conventional and Paraffinic Diesel Fuels, Flow, Turbulence and Combustion, Volume 96, Issue 2, March 2016, pp 327-341. DOI 10.1007/s10494-015-9644y.

12. C.K. Gaddam, R.L. Vander Wal, Physical and chemical characterization of SIDI engine particulates, Combustion and Flame, Volume 160, Issue 11, November 2013, Pages 2517-2528, ISSN 0010-2180, http://dx.doi.org/10.1016/j.combustflame.2013.05.025.

13. Y. Jung, C. Bae, Immaturity of soot particles in exhaust gas for low temperature diesel combustion in a direct injection compression ignition engine, Fuel, Volume 161, 1 December 2015, Pages 312-322, ISSN 0016-2361, http://dx.doi.org/10.1016/j.fuel.2015.08.068.

14. Z. Li, C. Song, J. Song, G. Lv, S. Dong, Z. Zhao, Evolution of the nanostructure, fractal dimension and size of in-cylinder soot during diesel combustion process, Combustion and Flame, 
Volume 158, Issue 8, August 2011, Pages 1624-1630, ISSN 0010-2180,

http://dx.doi.org/10.1016/j.combustflame.2010.12.006.

15. Neer, U.O. Koylu, Effect of operating conditions on the size, morphology, and concentration of submicrometer particulates emitted from a diesel engine, Combustion and Flame, Volume 146, Issues 1-2, July 2006, Pages 142-154, ISSN 0010-2180, http://dx.doi.org/10.1016/j.combustflame.2006.04.003.

16. M. Alfè, B. Apicella, J.N. Rouzaud, A. Tregrossi, A. Ciajolo, The effect of temperature on soot properties in premixed methane flames, Combustion and Flame, Volume 157, Issue 10, October 2010, Pages 1959-1965, ISSN 0010-2180, http://dx.doi.org/10.1016/j.combustflame.2010.02.007.

17. M.F. Chandler, Y. Teng, U. Koylu, Diesel engine particulate emissions: A comparison of mobility and microscopy size measurements, Proceedings of the Combustion Institute, Volume 31, Issue 2, January 2007, Pages 2971-2979, ISSN 1540-7489, http://dx.doi.org/10.1016/j.proci.2006.07.200.

18. M. Lapuerta, F.J. Martos, J.M. Herreros, Effect of engine operating conditions on the size of primary particles composing diesel soot agglomerates, Journal of Aerosol Science, Volume 38, Issue 4, April 2007, Pages 455-466, ISSN 0021-8502, http://dx.doi.org/10.1016/j.jaerosci.2007.02.001.

19. M. Lapuerta, F. Oliva, J.R. Aguedelo, A.L. Boehman, Effect of fuel on the soot nanostructure and consequences on loading and regeneration of diesel particulate filters, Combustion and Flame, Volume 159, Issue 2, February 2012, Pages 844-853, ISSN 0010-2180, http://dx.doi.org/10.1016/j.combustflame.2011.09.003.

20. N. Nejar, M. Makkee, M.J. Illián-Gómez, Catalytic removal of NOx and soot from diesel exhaust: Oxidation behaviour of carbon materials used as model soot, Applied Catalysis B: 
Environmental, Volume 75, Issues 1-2, 29 August 2007, Pages 11-16, ISSN 0926-3373, http://dx.doi.org/10.1016/j.apcatb.2007.03.009.

21. D. Uy, M.A. Ford, D.T. Jayne, A.E. O’Neill, L.P. Haack, J. Hangas, M.J. Janger, A. Sammut, A.K. Gangopadhyay, Characterization of gasoline soot and comparison to diesel soot: Morphology, chemistry, and wear, Tribology International, Volume 80, December 2014, Pages 198-209, ISSN 0301-679X, http://dx.doi.org/10.1016/j.triboint.2014.06.009.

22. M.M. Maricq, Chemical characterization of particulate emissions from diesel engines: A review, Journal of Aerosol Science, Volume 38, Issue 11, November 2007, Pages 1079-1118, ISSN 0021-8502, http://dx.doi.org/10.1016/j.jaerosci.2007.08.001.

23. B. Yang, X. Wei, C. Xi, Y. Liu, K. Zeng, M. Lai. Experimental study of the effects of natural gas injection timing on the combustion performance and emissions of a turbocharged common rail dual-fuel engine, Energy Conversion and Management, Volume 87, November 2014, Pages 297304, ISSN 0196-8904, http://dx.doi.org/10.1016/j.enconman.2014.07.030.

24. M. Constantine, A. Dobbins Richard, Comparison of Soot Growth and Oxidation in Smoking and Non-Smoking Ethylene Diffusion Flames, Combustion Science and Technology, Volume 66, Issue 1-3, 1989, pp 1-16. DOI:10.1080/00102208908947136.

25. K. Park, D. Kittelson, P. McMurry, Relationship between Particle Mass and Mobility for Diesel Exhaust Particles, Environmental Science \& Technology 200337 (3), 577-583. DOI: $10.1021 / \mathrm{es} 025960 \mathrm{v}$.

26. J. Appel, H. Bockhorn, and M. Frenklach. Kinetic modeling of soot formation with detailed chemistry and physics: laminar premixed flames of C2 hydrocarbons, Combustion and Flame, Volume 121, Issues 1-2, April 2000, Pages 122-136, ISSN 0010-2180, http://dx.doi.org/10.1016/S0010-2180(99)00135-2. 
27. J. Song, M. Alam, A. L. Boehman, U. Kim. Examination of the oxidation behavior of biodiesel soot, Combustion and Flame, Volume 146, Issue 4, September 2006, Pages 589-604, ISSN 00102180, http://dx.doi.org/10.1016/j.combustflame.2006.06.010.

28. L. Wang, C. Song, J. Song, G. Lv, H. Pang, W. Zhang, Aliphatic C-H and oxygenated surface functional groups of diesel in-cylinder soot: Characterizations and impact on soot oxidation behavior, Proceedings of the Combustion Institute, Volume 34, Issue 2, 2013, Pages 3099-3106, ISSN 1540-7489, http://dx.doi.org/10.1016/j.proci.2012.07.052. 


\section{List of Table Captions}

Table 1. Test conditions (1200 RPM, 20 mg/cycle load)

Table 2. TGA heating program

Table 3. Combustion characteristics and emission of tested fuels

Table 4. Statistics of Spherule Diameter from Tested Fuels (Unit: nm)

\section{List of Figure Captions}

Figure 1. In-cylinder pressure of soot samples

Figure 2. TGA profiles (mass \% lost) of soot samples

Figure 3. Typical TEM images of soot samples

Figure 4. Relationship between spherules per aggregate and aggregate size

Figure 5. Normalized spherule size distributions

Figure 6. Typical HRTEM images of (a) diesel (b) CNG40 (c) CNG70

Figure 7. Raman spectra of soot samples

Figure 8. DRIFT spectra of soot samples 